to be correct. In a pilot study, we measured EBC-adenosine levels in eight nonasthmatic patients with allergic rhinitis. At the time of the measurement all patients were exposed to natural allergens and had symptoms of rhinitis. Adenosine concentrations were significantly higher in samples from these patients than in samples from healthy subjects. This result confirms that active allergic inflammation, either of the upper or lower airways, may result in elevation in EBC-adenosine concentration as suggested. Furthermore, when EBC was collected with nasal inhalation adenosine levels were higher than in samples obtained with oral inhalation, suggesting that nasally produced adenosine may enter the lower airways which may, at least in part, be responsible for increases in the adenosine levels [8].

Finally, we agree with L. Spicuzza and colleagues that there is a need for further prospective studies on this topic. We believe these studies need to assess changes in the concentration of adenosine in exhaled breath condensate and also evaluate the relationship between adenosine in exhaled breath condensate and the degree of allergen exposure or deterioration in airway inflammation. Justification of the possible use of the concentration of adenosine in exhaled breath condensate to monitor chronic or acute airway inflammation also requires further investigation.

\section{É. Huszár, I. Horváth}

Dept of Pathophysiology, National Korányi Institute for Tuberculosis and Pulmonology, Budapest, Hungary.

\section{References}

1. Driver AG, Kukoly CA, Ali S, Mustafa SJ. Adenosine in bronchoalveolar lavage fluid in asthma. Am Rev Respir Dis 1993; 148: 91-97.

2. Barát E, Huszár É, Vass G, Csiszér E, Valyon M, Horváth I. Measurement of natrium chloride and adenosine concentration in exhaled breath condensate. Eur Respir J 2002; 20: Suppl. 38, 281s.

3. Polosa R, Ciamarra I, Mangano G, et al. Bronchial hyperresponsiveness and airway inflammation markers in nonasthmatics with allergic rhinitis. Eur Respir $J$ 2000; 15: 30-35.

4. Polosa R, Holgate ST. Adenosine bronchoprovocation: a promising marker of allergic inflammation in asthma? Thorax 1997; 52: 919-923.

5. van den Berge M, Meijer RJ, Kerstjens HA, et al. PC20 adenosine $5^{\prime}$-monohosphate is more closely associated with airway inflammation in asthma than PC20 methacholine. Am J Respir Crit Care Med 2000; 163: 1546-1550.

6. Huszár É, Horváth I, Barát E, Herjavecz I, BöszörményiNagy Gy, Kollai M. Elevated circulating adenosine level potentiates antigen-induced immediate bronchospasm and bronchoconstrictor mediator release in sensitized guinea pigs. J Allergy Clin Immunol 1998; 102: 687-691.

7. Csoma Zs, Vizi É, Huszár É. Post-exercise changes in FEV1 values and in adenosine concentrations in exhaledbreath condensate in healthy subjects and patients with exerciseinduced asthma. Eur Respir J 2002; 20: Suppl. 38, 290s.

8. Vass G, Huszár É, Barát E, et al. Comparison of nasal and oral inhalation during exhaled breath condensate collection. Am J Respir Crit Care Med 2002; 167: 850-855.

\title{
Exhaled breath temperature in airways disease
}

\section{To the Editor:}

It was with interest that we read the study of PAREDI et al. [1] which reports a slower rise in exhaled breath temperature in patients with chronic obstructive pulmonary disease (COPD). It is intriguing to think that altered airway heat transfer may provide a noninvasive marker of airways inflammation or remodelling. However, heat transfer in the airway has long been known to be a complex process and we feel this study leaves important questions unanswered.

The authors hypothesise that patients with COPD have alterations in bronchial blood flow that affect the rise in exhaled air temperature. Heat transfer in the airways in the context of respiratory disease was studied by WALKER et al. [2] in 1961, and since in COPD [3], cystic fibrosis [4] and thermally induced asthma [5]. There is still controversy over the relative roles of the upper airway, bronchial circulation and pulmonary circulation in airway heat exchange. Under conditions of high ventilation, the work of BAILE et al. [6], Solway et al. [7] and, more recently, SERIKOV and Fleming [8] showed pulmonary circulation to be the dominant heat source to the airways. Furthermore, using invasive measurements of intra-airway temperature, MCFADDEN et al. [9] showed that airways down to subsegmental level are actively involved in heat exchange only at high minute ventilation with extremely cold inspired air. In contrast, when breathing indoor room air at normal tidal flow rates, virtually all heat transfer occurs in the upper airway (above the glottis) [10]. It has therefore yet to be established whether changes in bronchial blood flow caused by disease are a significant determinant of breath temperature under normal ambient conditions. In the study of PAREDI et al. [1], subjects were respiring warm room air $\left(21-23^{\circ} \mathrm{C}\right)$ at low flow rates $\left(10 \mathrm{~L} \cdot \mathrm{min}^{-1}\right)$. Previous work would suggest that the airway below the glottis (which the authors seek to test) would not be contributing significantly to heat exchange under these conditions.

Regarding the methodology of the temperature washout technique, the authors acknowledge the extreme sensitivity of the rate of temperature rise to expiratory flow rate but do not report the method of flow targeting or indeed the flow rates achieved in controls versus COPD groups. Expiratory flow patterns rather than airway heat transfer may therefore contribute to the differences seen between the groups and are crucial to the interpretation of the temperature washout data. Finally, heat is consumed in two ways during inspiration: $\sim 25 \%$ of the energy is used in heating the air (convective) and $75 \%$ in evaporating moisture from the mucosal surface to humidify the air stream (evaporative). On expiration, the reverse of both processes occurs, namely, convective cooling and condensation of water vapour on the mucosa. This dominance of energy transfer through evaporation and condensation suggests that attempts to characterise the thermodynamic performance of the airways by temperature measurement alone, without accompanying humidity measurements, may be misleading.

As with all new noninvasive breath measurements, it is important that methods and protocols are standardised and 
optimised in a way that takes into account the known underlying physical mechanisms.

\section{J.B. McCafferty, J.A. Innes}

University of Edinburgh, Respiratory Unit, Western General Hospital, Edinburgh, UK.

\section{References}

1. Paredi P, Caramori G, Cramer D, et al. Slower rise of exhaled breath temperature in chronic obstructive pulmonary disease. Eur Respir $J$ 2003; 21: 439-443.

2. Walker JE, Wells CRE, Merrill EW. Heat and water exchange in the respiratory tract. Am J Med 1961; 30: 259267.

3. Caldwell PRB, Gomez DM, Fritts HW Jr, et al. Respiratory heat exchange in normal subjects and in patients with pulmonary disease. J Appl Physiol 1969; 26: 82-88.

4. Primiano FP, Saidel GM, Montague FW Jr, Kruse KL, Green CG, Horowitz JG. Water vapour and temperature dynamics in the upper airways of normal and CF subjects. Eur Respir J 1988; 1: 407-414.

5. Gilbert IA, Fouke JM, McFadden ER Jr. Heat and water flux in the intrathoracic airways and exercise-induced asthma. J Appl Physiol 1987; 63: 1681-1691.

6. Baile EM, Dahlby RW, Wiggs BR, Pare PD. Role of tracheal and bronchial circulation in respiratory heat exchange. J Appl Physiol 1985; 58: 217-222.

7. Solway J, Leff ID, Dresha I, et al. Circulatory heat sources for canine respiratory heat exchange. J Clin Invest 1986; 78: $1015-1019$.

8. Serikov VB, Fleming NW. Pulmonary and bronchial circulations: contributions to heat and water exchange in isolated lungs. J Appl Physiol 2001; 91: 1977-1985.

9. McFadden ER Jr, Pichurko BM, Bowman KF, et al. Thermal mapping of the airways in humans. J Appl Physiol 1985; 58: 564-570.

10. Cole P. Further observations on conditioning of respiratory air. J Laryngol Otol 1953; 67: 669-681.

\section{From the authors.}

We would like to thank J.B. McCafferty and J.A. Innes for their interest and constructive criticism relating to our paper which reported low exhaled breath temperature gradients in chronic obstructive pulmonary disease patients compared to normal subjects [1].

J.B. McCafferty and J.A. Innes suggest that it is controversial that bronchial blood flow has a role in airway heat exchange. We disagree and would like to draw their attention to numerous papers that demonstrated the opposite effect. First, it has been shown that changes in airway blood volume are reflected in fluctuations in intra-thoracic heat exchange, whereas even large increases in blood flow through the pulmonary circulation do not influence airstream temperature [2]. This proves that bronchial and not pulmonary blood flow plays a major role in airway heat exchange. Secondly, changes in bronchial blood flow can alter airway responsiveness and temperature [3], confirming that the bronchial circulation may control airstream temperature and contribute to airway narrowing. Thirdly, temperature changes induce bronchoconstriction, which can be prevented by reducing mucosal blood supply using inhaled vasoconstrictors [3], indicating that airway temperature and bronchial blood flow are correlated. Furthermore, preliminary data presented as an oral presentation at the American Thoracic Society meeting in Atlanta last year by our group showed a correlation between bronchial blood flow, measured noninvasively by an inhaled soluble gas technique, and exhaled breath temperature gradients [4]. Therefore, there is substantial evidence that airway blood flow is the major determinant of airway heat exchange.

In their letter, J.B. McCafferty and J.A. Innes also state that heat transfer occurs in the upper airways (above the glottis) when breathing normally at room temperature. They quote a manuscript published in 1953 by COLE [5], but they have not interpreted the manuscript correctly and have ignored more recent publications by the same author. Even though we agree that inspired air is mostly conditioned in the upper airways, in our study we concentrated on exhaled air. The work of COLE [6] has demonstrated that "during expiration heat and water are returned to the exhaled air along the whole of the respiratory tract", including the bronchial tree. We would also like to stress that the patients included in our study, as described in the method session, were not "respiring at low flow rates" as indicated by J.B. McCafferty and J.A. Innes. Rather, they were breathing normally at tidal volume before being asked to exhale at a constant exhalation flow rate $\left(10 \mathrm{~L} \cdot \mathrm{min}^{-1}\right)$ after a deep inhalation to total lung capacity.

Regarding the methodology for the measurement of exhaled breath temperature gradients, J.B. McCafferty and J.A. Innes point out that we did not report the method of flow targeting. However, after describing the exhalation manoeuvre as flow and pressure controlled, we refer the reader to a previous publication by our group in which all the details related to the pressure $\left(4 \mathrm{cmH}_{2} \mathrm{O}\right)$ and flow control (visual feedback) are fully described (see reference [14] in the text of [1]).

J.B. McCafferty and J.A. Innes make further comments regarding our manuscript stating that because we did not control the exhalation flow rate our measurements actually reflect expiratory pattern rather than heat exchange. However, we did control exhalation flow rate (see above and see the Methods section in the manuscript [1]). Furthermore, a more thorough reading of the literature would have shown that expiratory air at the mouth is little influenced by ventilation rate [6] and pattern (tidal volume and respiratory rate changes with the same minute ventilation) [7].

We agree that the measurement of humidity of the exhaled breath would add important information related to the balance between airway temperature and evaporation of epithelial lining fluid in the airways. We are therefore currently developing a new method for the measurement of exhaled breath humidity. For the standardisation of the method (exhalation flow rate, mouth pressure, distance of the thermocouple from the mouthpiece, body core temperature, room temperature, etc.) we refer J.B. McCafferty and J.A. Innes to references [13] and [14] in our manuscript [1].

\section{P. Paredi, S.A. Kharitonov, P.J. Barnes}

Dept of Thoracic Medicine, Imperial College School of Medicine at the National Heart and Lung Institute, London, UK.

\section{References}

1. Paredi P, Caramori G, Cramer D, Ward S, Kharitonov SA, Barnes PJ. Slower rise of exhaled breath temperature in COPD. Eur Respir J 2003; 21: 439-443.

2. Gilbert IA, Regnard J, Lenner KA, Nelson JA, McFadden ERJ. Intrathoracic airstream temperatures during acute 